УДК 622.279 .5

DOI: $10.31471 / 1993-9973-2020-1(74)-82-88$

\title{
ОСОБЛИВОСТІ ВІДТВОРЕННЯ РІВНЯННЯ СТАНУ ГАЗОКОНДЕНСАТНИХ СУМІШЕЙ ЗА УМОВИ ОБМЕЖЕНОЇ ВХІДНОЇ ІНФОРМАЦІї
}

\author{
О. В. Бурачок ${ }^{1}$, Д. В. Периин ${ }^{2}$, С. В. Матківський ${ }^{2}$, С. С. Бікман ${ }^{2}$, О. Р. Кондрат ${ }^{3}$ \\ ${ }^{1}$ Schlumberger GmbH, 30177 Hannover Germany, Guenther-Wagner-Allee 19 \\ e-mail: oburachok@slb.com
}

\begin{abstract}
${ }^{2}$ Украӥнський науково-дослідний інститут природних газів; 61010, м. Харків, Гімназійна набережна, 20,тел./факс (05773) 3-17-55, e-mail:dmytro.pershyn@ndigas.com.ua,matkivskyi.sergey@ndigas.com.ua, bikman.efim@ndigas.com.ua
\end{abstract}

\author{
${ }^{3}$ ІФНТУНГ; 76019, м. Івано-Франківськ, вул. Карпатська, 15, тел./факс (03422) 42195, \\ e-mail: kondrat@nung.edu.ua
}

\begin{abstract}
Охарактеризовано основні складнощі, які виникають при відтворенні фазових перетворень, щуо описуються моделлю «чорної нафти», або повнофункиіональною композиційною моделлю за допомогою рівняння стану з метою створення коректних постійно діючих геолого-технологічних ЗД моделей газоконденсатних родовищ. Вихідними даними для побудови фільтрачійних ЗД моделей родовищ, розробка яких розпочалась щее в 1960-х роках, є результати початкових газоконденсатних та термодинамічних досліджень. Вуглеводневий компонентний склад пластового газу наявних газоконденсатних досліджень приводиться тільки до фракиії $C_{5+}$. Враховуючи особливості проведення початкових термодинамічних досліджень з використанням експерименту диференціальної конденсаиї та відсутності такого експерименту в переліку стандартних експериментів у комериійно-доступних PVT-симуляторах, виникла необхідність розроблення раціональних підходів та методик, які б допомогли коректно використовувати наявну геолого-промислову інформаціюо для побудови PVT-моделей. В даній статті описано методику відтворення рівняння стану РепяRobinson за умов обмеженої вхідної інформації. Залежно від наявності вихідних даних та їх якості для адекватного відтворення рівняння стану авторами запропоновано та використано два різні підходи. Периий підхід до побудови PVT-моделі, який дозволяє відтворити рівняння стану, базується на даних компонентного складу газів та фракційного складу стабільного конденсату. Другий підхід передбачає у разі відсутності фракційного складу стабільного конденсату розбиття фракиії $C_{5+}$ з використанням об' ємного методу Вітсона. Запропонована методика та різні підходи до відтворення рівняння стану дозволяють ефективно створювати PVT-моделі використовуючи наявну геолого-промислову інформацію. Результати проведених досліджень представлено у вигляді графічних залежностей порівняння динаміки потенційного вмісту вуглеводнів $C_{5_{+}} 6$ пластовому газі до та після налаштування рівняння стану, а також результати налаштування синтетичної кривої втрат "Liquid saturation” CVD експеримента.
\end{abstract}

Ключові слова: газоконденсатні дослідження, термодинамічні дослідження, фазові перетворення, PVTмоделі.

Описаны основные проблемы, возникающие при воспроизведении фазовых превращений пластовых газоконденсатных систем, описываемых моделью «черной нефти» или полнофункциональной композиционной моделью с помощью уравнения состояния с иелью создания корректных фильтраичонных $3 D$-моделей газоконденсатных месторождений. Исходными данными для фильтрационных $3 D$ моделей месторождений, разработка которых началась еще в 1960-х годах, являются результаты начальных газоконденсатных и термодинамических исследований. Компонентный состав пластового газа имеющихся газоконденсатных исследований приводится только до фракции $C_{5+}$. Учитывая особенности проведения начальных термодинамических исследований с использованием эксперимента дифференцииальной конденсации и отсутствие этого эксперимента в перечне стандартных экспериментов в коммерчески-доступных PVT-симуляторах, возникла необходимость создания рачиональных подходов и методик, которые могли бы корректно использовать имеющуюся геолого-промысловую информацию для создания PVT-моделей. В данной статье описана методика настройки уравнения состояния Peng-Robinson в условиях ограниченной исходной информации. В зависимости от наличия исходных данных и их качества для адекватной настройки уравнения состояния авторами предлагается и используется два разных подхода. Первый подход для создания PVT-модели, позволяющчй настрочть уравнение состояния, основывается на наличии компонентного 
состава газов и фракционного состава стабильного конденсата. Второй подход предусматривает, в случае отсутствия фракционного состава стабильного конденсата, разбиение фракции $C_{5+} c$ использованием объемного метода Витсона. Предложенная методика и два разных подхода для настройки уравнения состояния позволяют эффективно создавать PVT-модели, используя имеюшуюся геолого-промысловую информацию. Результаты исследований представлены в виде графических зависимостей сравнения динамики потеничиального содержания углеводородов $C_{5+}$ в пластовом газе до и после настройки уравнения состояния, а также результаты настройки синтетической кривой потерь "Liquid saturation" CVD эксперимента.

Ключевые слова: газоконденсатные исследования, термодинамические исследования, фазовые превращения, РVT-модели.

The article characterizes the key difficulties which emerge during the simulation of phase behaviors described using the model of "black oil" or fully functional compositional model with the help of the equation-of-state (EOS) in order to create valid continuously operating geological-technological 3D models of gas-condensate reservoirs. The input data for $3 D$ filtration reservoir modeling, the development of which started in the 1960s, are the results of initial gas-condensate and thermodynamic studies. Hydrocarbon component composition of reservoir gas in the existing gas-condensate studies is given only to fraction $C_{5+}$. Taking into account the peculiarities of initial thermodynamic research with the use of the differential condensation experiment and the absence of such type of experiment in the list of standard experiments in commercially-available PVT-simulators, there appeared a need to develop rational approaches and techniques for correct integration of existing geological-production data in PVT modeling. This article describes the methods for adjusting Peng-Robinson equation-of-state under the condition of input data shortage. Depending on initial data availability and quality, the authors have suggested two different methods. The first PVT-modeling method, which makes it possible to adjust the equation-of-state, is based on the data of component composition of gases and fractional composition of the stable condensate. In case the data of fractional composition of the stable condensate are not available, the authors suggest the second method that is the splitting of fraction $C_{5+}$ following Whitson volumetric methodology. The suggested methods and two different approaches to EOS adjustment allow effective PVT-modeling using available geological and production data. Study results are presented as the graphical dependencies of comparison of potential hydrocarbons $C_{5+}$ content change in reservoir gas before and after configuring the equation-of-state, as well as the synthetic "liquid saturation" loss curve of the CVD experiment.

Keywords: gas-condensate studies, thermodynamic studies, phase behavior, PVT-models.

\section{Вступ}

Створення фільтраційних ЗД моделей родовищ нафти та газу неможливе без коректного відтворення фазових перетворень, що описуються моделлю флюїдів у спрощеному вигляді табличної залежності «модель чорної нафти», або повнофункціональній композиційній моделі за допомогою рівняння стану. У випадку моделі чорної нафти, для більшості випадків, розрахунок динаміки в'язкості, газовмісту та об'ємного коефіцієнта можна зробити за однієї iз запропонованих кореляцій, таких як Standing, Valko та ін. [6]. У випадку газоконденсатних систем із високим потенційним вмістом рідких вуглеводнів, що розробляються з підтриманням пластового тиску за допомогою вуглеводневих і невуглеводневих газових агентів, або пластових систем, що відносяться до критичних, складні фазові перетворення ретроградної конденсації можна коректно описати тільки за допомогою рівнянь стану. В промисловій практиці найбільшого поширення набули трипараметричні рівняння Peng-Robinson (PR) та SoaveRedlich-Kwong (SRK), які реалізовані в усіх комерційних гідродинамічних симуляторах компаній (Schlumberger, CMG, RFD, Roxar, Halliburton i т.д.). Оскільки фізичні властивості та компонентний склад відомий тільки до пев- ної плюсової фракції, налаштування рівняння стану здійснюється у спеціальному програмному забезпеченні - PVT симуляторі, яких є також достатньо багато на ринку. Дані проблеми не $є$ новими і різними авторами реалізовані різні підходи до їх розв'язання $[2,4,8]$. У даній роботі описано методику відтворення рівняння стану PR за умов обмеженої вхідної інформації, a саме наявністю компонентного складу пластового газу тільки до $\mathrm{C}_{5+}$, особливостями проведення початкових термодинамічних досліджень 3 використанням експерименту диференціальної конденсації та відсутності такого експерименту в переліку стандартних експериментів у комерційно-доступних PVT-симуляTopax.

\section{Постановка проблеми}

Вихідними даними для побудови моделей родовищ, розробка яких розпочалась в 19601980-х роках, є результати початкових газоконденсатних (ГК) та термодинамічних досліджень (ТД), які проводились відповідно до діючих на час проведення інструкцій [9].

Аналіз наявних даних щодо початкових ГК і ТД газоконденсатних покладів більше 20 родовищ ДДЗ виявив наступні проблеми, вирішення яких дозволило створити адекватну 
методику побудови PVT-моделі пластового флюїду.

1. Компонентний склад пластового газу відомий тільки до нормального- і ізо-бутана, решта компонентів характеризується як $\mathrm{C}_{5+}$, в той час, як класичні методики розбиття на псевдофракції у комерційних продуктах базуються на фракції $\mathrm{C}_{7_{+}}$і вищому групуванні.

2. Хроматографічний аналіз стабільного конденсату (вуглеводнів $\mathrm{C}_{5+}$ ), практично, не проводився. Зазвичай визначено густину, кінематичну в'язкість, молекулярну масу та фракційний склад стабільного конденсату за Енглером (аналог ASTM D86).

3. PVT-властивості пластового флюїду визначались за експериментом диференціальної конденсації на установці фазової рівноваги типу УГК-3. В комерційних РVT-симуляторах цей метод не реалізований, оскільки у світових лабораторіях такий експеримент не проводиться. Там для опису поведінки пластових газоконденсатних систем використовують рівноважні експерименти: а) за постійного об'єму (CVD constant volume depletion), коли після збільшення об'єму бомби та випадіння рідкої фази, газ стравлють повертаючи об'єм бомби до об'єму за тиску початку конденсації, визначаючи компонентний склад газу з використанням газохроматографічного аналізу; б) за постійного складу (СCE - constant composition expansion), де об'єм бомби збільшується покроково без стравлювання газу. Аналогом експерименту CСЕ $є$ експеримент контактної конденсації, але цей експеримент, практично, не проводився. За результатами експерименту диференціальної конденсації в бомбі УГК-3 визначались пластові втрати конденсату в $\mathrm{cm}^{3} / \mathrm{m}^{3}$ газу сепарації. За результатами експерименту CVD кількість конденсату, що випав визначається в процентах відносно об' єму PVT-комірки за тиску початку конденсації.

Таким чином, виникає питання, як використати наявну інформацію для створення адекватного рівняння стану.

\section{Запропонована методика розрахунку}

Першим кроком $є$ оцінка репрезентативності результатів початкових газоконденсатних (ГК) та термодинамічних досліджень. На якість результатів цих початкових досліджень впливає багато факторів: початкові дослідження мають проводитись в початковий період експлуатації свердловини після освоєння (залежно від параметрів роботи свердловини від двох тижнів до 2-3 місяців стабільної експлуатації свердловини в шлейф); свердловина перед дослідженнями має бути очищена від продуктів буріння; повинна бути відсутня пластова вода; швидкість газорідинного потоку в стовбурі свердловини має забезпечувати повний винос рідини 3 вибою на поверхню; депресія на пласт не повинна перевищувати $10 \%$ від початкового пластового тиску; для недонасичених систем вибійний тиск має бути вищим за тиск початку конденсації.

Залежно від наявності вихідних даних для адекватного відтворення рівняння стану, авторами запропоновано та використано два різні підходи.

\section{Пidxid 1}

У випадку наявності компонентного складу газів сепарації, дегазації, дебутанізації та результатів фракційної розгонки стабільного конденсату створюється компонентнофракційний склад пластової вуглеводневої системи. Це здійснюється аналітичним методом [10], або використанням спеціалізованого програмного забезпечення («Газконднефть», Aspen Hysys, тощо). Це дозволяє отримати компонентний склад пластового газу $\mathrm{N}_{2}, \mathrm{CO}_{2}, \mathrm{C}_{1}-\mathrm{C}_{4}$, та певної кількості фракцій (від 5 до 11) з відомими молекулярними масами кожної з них.

Далі на основі отриманого компонентного складу відтворюється рівняння стану в РVTсимуляторі. В даному випадку використаний програмний модуль PVTi компанії Schlumberger. Для опису фазової поведінки перевага надавалася трипараметричному рівнянню стану Пенга-Робінсона, для якого розрахункова критична стисливість газу $є$ найнижчою порівняно 3 іншими загально прийнятими рівняннями та становить 0.307. Слід відмітити, що для вуглеводневих газів ця величина нижча за 0.29 .

Єдиним варіантом задання результатів диференціальної конденсації - $\epsilon$ використання кривої втрат за насиченням по рідині (liquid saturation) у CVD експерименті. Однак, зважаючи на те, що диференціальна конденсація $\epsilon$ нерівноважним процесом [10], кількість рідких вуглеводнів, що випали в комірці PVT є заниженою в порівнянні $з$ тою, яка має бути в рівноважному CVD-експерименті. Тому напряму криву втрат вуглеводнів використовувати не можна. Крім того, для іiі розрахунку необхідно знати точний об' єм комірки PVT на етапі зниження тиску до тиску початку конденсації, що в звітах про проведені експерименти 3 диференціальної конденсації відсутне.

Тому на цьому етапі порівнюється тиск початку конденсації, отриманий при проведен- 
ні експерименту диференціальної конденсації 3 розрахунковим значенням, отриманим із рівняння стану для початкових критичних параметрів компонентів.

Додатковими експериментами для налаштування рівняння стану $є$ багато-ступеневий експеримент на сепараторі (SEP), за яким налаштовується конденсатогазовий фактор по нестабільниму та стабільному конденсату за певних термобаричних умов сепарації під час проведення промислових досліджень на газоконденсатність, а також густина стабільного конденсату, яка визначається за стандартних умов. Також проводиться налаштування значення тиску початку конденсації у одноступеневому експерименті (DEW). Налаштування рівняння стану до експериментальних даних $\epsilon$ скоріш “мистецтвом", ніж чітко визначений науковий підхід і в значній мірі залежить від досвіду інженера, що його безпосередньо проводить. Загальні рекомендації описано різними дослідниками, вченими та промисловиками, серед яких слід виділити роботи Вітсона, Коутса, Педерсона, Брусиловського та ін. [2-8].

В якості параметрів регресії для налаштування рівняння стану на експериментальні дані авторами використано:

- для тиску початку конденсації - критичні тиск і температура для_кількох найважчих псевдокомпонентів;

- для кривої втрат (випадіння важких вуглеводнів, Liquid Saturation) - Омега А і Омега Б для псевдокомпонентів і коефіцієнт бінарної взаємодії між C1 і найважчим псевдокомпонентом.

Після цього за результатами налаштування експерименту CVD на основі розрахункового компонентного складу газової фази розраховується динаміка потенційного вмісту вуглеводнів $\mathrm{C}_{5+}$ в пластовому (видобувному) газі, яку порівнюється 3 прийнятою кривою динаміки потенційного вмісту вуглеводнів $\mathrm{C}_{5+}$ в пластовому газі. Залежно від отриманих результатів коригується криву втрат Liquid saturation i повторюється налаштування рівняння стану. Густину стабільного конденсату налаштовується параметром об' ємного зсуву.

\section{Пidxid 2}

За відсутності даних фракційного складу стабільного конденсату, або у випадках, коли PVT-модель створюється з метою використання у спрощеному вигляді (моделі “чорної нафти”), розбиття $\mathrm{C}_{5+}$ можна здійснювати 3 використанням об'ємного методу Вітсона [7], відомого також як напів-послідовний термодинамі- чний розподіл (у PVTi - Multi-feed split), де необхідно зазначити мінімальну молярну вагу “+” фракції, молярну вагу найважчого компонента та вибрати кореляцію для критичних параметрів і ацентричного фактора. В нашому випадку розбиття здійснювалося на 5 псевдокомпонентів 3 використанням кореляцій Кеслера-Лі (Kesler-Lee). Через меншу кількість псевдокомпонентів ніж у підході 1, для налаштування рівняння стану використовуються наступні параметри:

- відтворення тиску початку конденсації та кривої насичення - критична температура усіх псевдокомпонентів;

- для відтворення густини стабільного конденсату - об' ємний параметр зсуву для кількох найлегших псевдокомпонентів.

Після відтворення рівняння стану генеруються відповідні ключові слова для гідродинамічного симулятора для використання у композиційному моделюванні чи моделі «чорної нафти».

\section{Приклад застосування методики}

Нижче наведені результати відтворення рівняння стану для пластового флюїду одного 3 родовищ Дніпрово-Донецької западини з використанням підходу 2. Термодинамічні дослідження пластового флюїду даного покладу не проводились. Динаміку потенційного вмісту вуглеводнів $\mathrm{C}_{5+}$ в пластовому газі визначено за результатами історії поточних досліджень свердловин на газоконденсатність протягом періоду розробки покладу.

За результатами початкових досліджень на газоконденсатність початковий потенційним вміст вуглеводнів $\mathrm{C}_{5+}$ складає $150 \mathrm{r} / \mathrm{m}^{3}$ сухого газу. Результати розбиття фракції $\mathrm{C}_{5+}$ на псевдокомпоненти наведено в таблиці 1, фізикохімічні властивості газу та конденсату - в таблиці 2. Як видно 3 таблиці 1, максимальну молекулярну вагу найважчого псевдокомпонента FRC5 при розбитті було прийнято на рівні 295.

Основним критерієм якості відтворення рівняння стану є відтворення динаміки потенційного вмісту вуглеводнів $\mathrm{C}_{5+}$, розрахованої за результатами CVD-експеримента. На рисунку 1, наведено динаміку потенційного вмісту вуглеводнів $\mathrm{C}_{5+}$ до та після налаштування рівняння стану. Як бачимо, зелена крива чудово відтворює результати фактичних досліджень на газоконденсатність. На рисунку 2 наведено результат налаштування синтетичної кривої втрат (Liquid saturation). Точність відтворення інших величин (тиску початку конденсації, густини стабільного конденсату, конденсатогазового 
Таблиця 1 - Компонентний склад пластового газу

\begin{tabular}{|c|c|c|c|c|c|c|c|c|}
\hline \multicolumn{2}{|c|}{ Компонент } & \multicolumn{2}{|c|}{$\begin{array}{c}\text { Мольна частка, } \\
\%\end{array}$} & $\begin{array}{c}\text { Масова частка, } \\
\%\end{array}$ & \multicolumn{2}{|c|}{$\begin{array}{c}\text { Молекулярна маса, } \\
\text { а.о.м. }\end{array}$} & \multicolumn{2}{|c|}{ Відносна густина } \\
\hline & $\mathrm{N}_{2}$ & \multicolumn{2}{|c|}{0,628} & 0,797 & \multicolumn{2}{|c|}{28,013} & & \\
\hline & $\mathrm{CO}_{2}$ & \multicolumn{2}{|c|}{4,175} & 8,327 & \multicolumn{2}{|c|}{44,010} & & \\
\hline & $\mathrm{C}_{1}$ & \multicolumn{2}{|c|}{82,923} & 60,292 & \multicolumn{2}{|c|}{16,043} & & \\
\hline & $\mathrm{C}_{2}$ & \multicolumn{2}{|c|}{6,218} & 8,474 & \multicolumn{2}{|c|}{30,070} & & \\
\hline & $\mathrm{C}_{3}$ & \multicolumn{2}{|c|}{2,163} & 4,323 & \multicolumn{2}{|c|}{44,097} & & \\
\hline & $-\mathrm{C}_{4}$ & \multicolumn{2}{|c|}{0,233} & 0,614 & \multicolumn{2}{|c|}{58,124} & & \\
\hline & $1-C_{4}$ & \multicolumn{2}{|c|}{0,510} & 1,344 & \multicolumn{2}{|c|}{58,124} & & \\
\hline \multirow{5}{*}{$\mathrm{C}_{5+}$} & FRC1 & \multirow{5}{*}{3,150} & 0,795 & 2,626 & \multirow{5}{*}{110,88} & 72,9 & \multirow{5}{*}{0,7503} & 0,7037 \\
\hline & FRC2 & & 1,201 & 5,087 & & 93,5 & & 0,7279 \\
\hline & FRC3 & & 0,814 & 4,897 & & 132,7 & & 0,7632 \\
\hline & FRC4 & & 0,293 & 2.590 & & 195,3 & & 0,8042 \\
\hline & FRC5 & & 0,047 & 0,630 & & 295,0 & & 0,8504 \\
\hline
\end{tabular}

Таблиця 2 - Фізико-хімічні властивості пластового газу та стабільного конденсату

\begin{tabular}{|c|c|c|}
\hline \multicolumn{2}{|r|}{ Параметр } & Величина \\
\hline \multirow{2}{*}{ Пластовий газ } & Густина, кг/м ${ }^{3}$ & 0,917 \\
\hline & Молекулярна маса, а.о.м. & 22,066 \\
\hline \multirow{3}{*}{ Стабільний конденсат } & Густина, кг/м ${ }^{3}$ & 772,6 \\
\hline & Кінематична в’язкість при $20^{\circ} \mathrm{C}$, сПз & 1,092 \\
\hline & Молекулярна маса, а.о.м. & 123 \\
\hline
\end{tabular}

фактору по стабільному та нестабільному конденсату) наведено в таблиці 3.

\section{Висновки}

Запропонована методика дозволяє ефективно створювати PVT-моделі газоконденсатних систем із різним потенційним вмістом рідких вуглеводнів за обмеженої наявності вхідних даних, а саме:

- наявності вуглеводневого компонентного складу пластового газу лише до $\mathrm{C}_{5+;}$

- відсутності даних з компонентного складу рідкої фази за хроматографічних досліджень;

- відсутності результатів CVD-експерименту, але наявності репрезентативних результатів досліджень свердловин на газоконденсатність протягом розробки покладу.

Відтворене, таким чином, рівняння стану дозволяє оперативно вирішувати задачі оптимізації розробки родовищ за допомогою моделі «чорної нафти» або повнофункціональної композиційної моделі флюїдів. Слід зазначити, що для нових відкритих покладів із початковими пластовими тисками, створення достовірної PVT-моделі можливе лише за наявності репрезентативних проб із детальним компонетним складом та проведення повноцінних лабораторних досліджень, особливо CVD-експерименту.

\section{Jimepamypa}

1. ASTM D86-15. Standard test method for distillation of petroleum products and liquid fuels at atmospheric pressure. PA: ASTM International, 2015. (http://www.astm.org)

2. Брусиловский А.И. Методология и результаты применения кубических уравнений состояния для моделирования термодинамических свойств природных углеводородных флюидов. Актуальные вопросы исследований пластовых систем месторождений углеводородов: сб. науч. статей в 2 ч. М.: Газпром ВНИИГАЗ, 2011. ч. 2. с. 150-165. (Вести газовой науки).

3. Coats K.H., Smart G.T. (1986) Application of a regressionbased EOS PVT program to laboratory data, Society of Petroleum Engineers Reservoir Engineering, 1, 277-299.

4. Григорьев Б.А., Брусиловский А.И. Зинченко И.А. Математическое моделирование пластовых систем, уравнения состояния и фазовые равновесия пластовых флюидов и их компонентов. Вести газовой науки. 2016. № (28). C. 13-20.

5. Pedersen K.S. et al. (1989) Characterization of gascondensate mixtures, in: Chorn L.G., Mansoori G.A. (edited by) C7+ fraction characterization. New York, Taylor \& Francis, 137-152. 


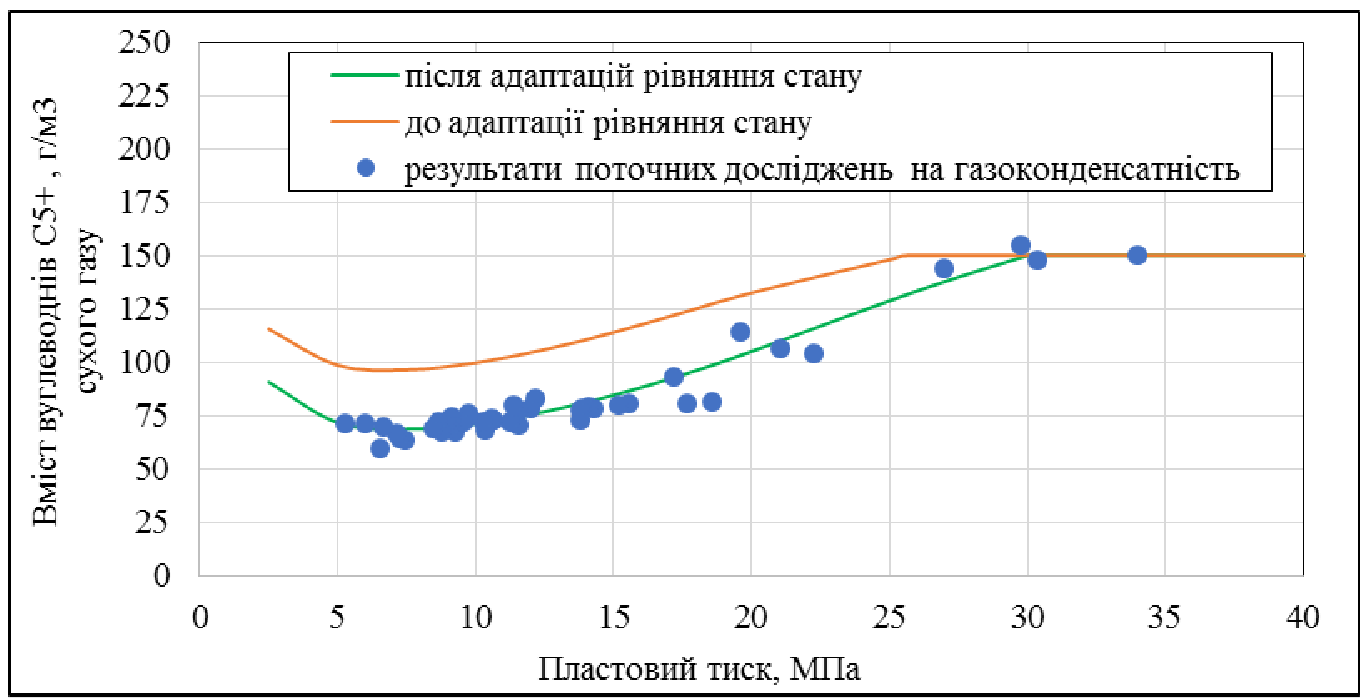

Рисунок 1 - Порівняння динаміки потенційного вмісту вуглеводнів $\mathrm{C}_{5+}$ в пластовому газі до та після налаштування рівняння стану

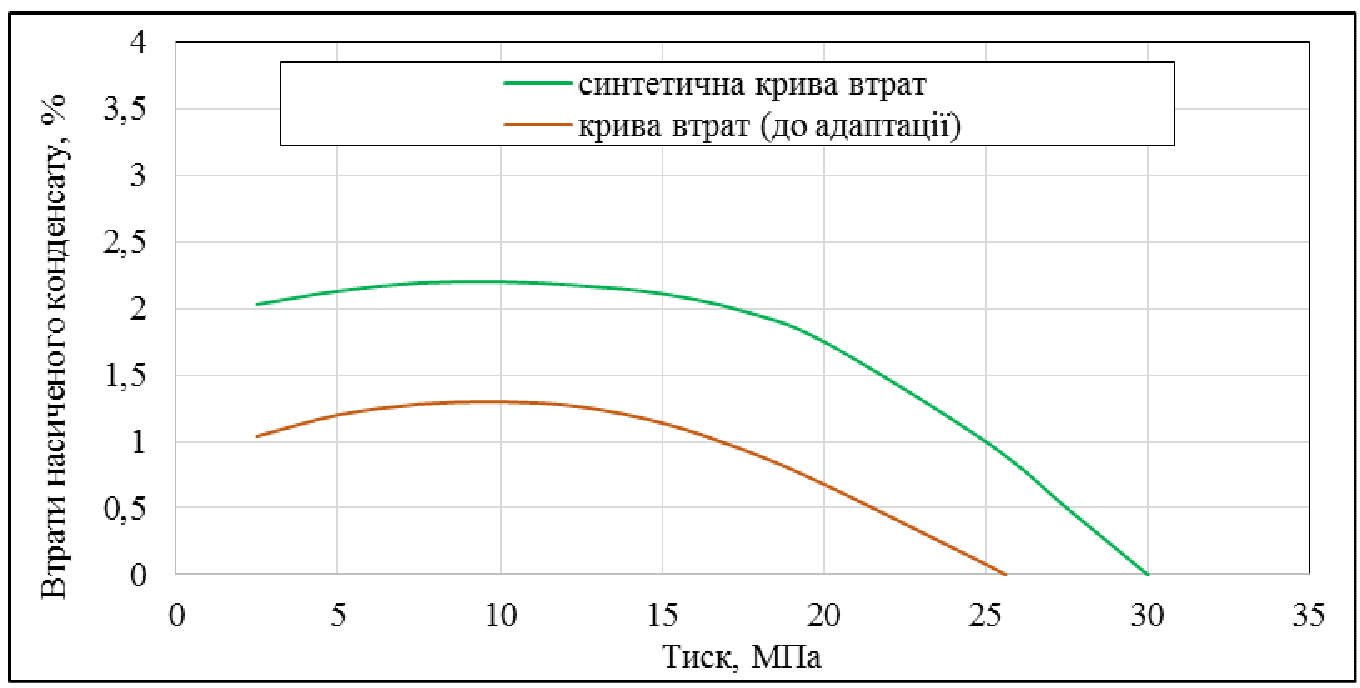

Рисунок 2 - Відтворення синтетичної кривої “Liquid saturation” CVD експеримента

Таблиця 3 - Порівняння заміряних та розрахункових за рівнянням стану значень параметрів, що використовувалися під час його налаштування

\begin{tabular}{|c|l|c|c|c|c|}
\hline $\begin{array}{c}\text { PVTi } \\
\text { експеримент }\end{array}$ & \multicolumn{1}{|c|}{ Параметр } & $\begin{array}{c}\text { Заміряне } \\
\text { значення }\end{array}$ & $\begin{array}{c}\text { Розрахункове } \\
\text { значення }\end{array}$ & $\begin{array}{c}\text { Одиниця } \\
\text { виміру }\end{array}$ & $\begin{array}{c}\text { Похибка, } \\
\%\end{array}$ \\
\hline DEW & Тиск початку конденсації & 300,00 & 300,01 & бар & 0 \\
\hline SEPS & Густина рідини & 772,6 & 772,1 & $\mathrm{\kappa} / \mathrm{m}^{3}$ & $0,06 \%$ \\
\hline SEPS & $\begin{array}{l}\text { Газоконденсатний фактор } \\
\text { нестабільного конденсату } \\
\text { (GOR) }\end{array}$ & 4352,0 & 4371,4 & $\mathrm{~m}^{3} / \mathrm{m}^{3}$ & $0,43 \%$ \\
\hline SEPS & $\begin{array}{l}\text { Газоконденсатний фактор } \\
\text { нестабільного конденсату } \\
\text { (ситulative GOR) }\end{array}$ & 5830,9 & 5719,4 & $\mathrm{~m}^{3} / \mathrm{m}^{3}$ & $1,91 \%$ \\
\hline
\end{tabular}


6. Whitson C.H., Brule M.R. Phase Behavior. SPE Monograph Series, Volume 20. Richardson, Texas, 2000. $240 \mathrm{p}$.

7. Whitson C. H. Characterizing Hydrocarbon Plus Fractions. SPE Reservoir Engineering. 1983. P. 683-694. (SPE 12233)

8. Ющенко Т.С., Брусиловский А.И. Эффективный метод построения и адаптации PVTмоделей пластовых флюидов газоконденсатных месторождений и газовых шапок нефтегазоконденсатных залежей. Нефтяное хозяйство. 2015. № 1. С. 56-60.

9. Зотов Г.А., Алиев 3.С. Инструкция по комплексному исследованию газовых и газоконденсатных пластов и скважин. М. Недра, 1980. $301 \mathrm{c}$.

10. Брусиловский А.И. Фазовые превращения при разработке месторождений нефти и газа. М.: Издательский дом «Грааль», 2002. $579 \mathrm{c}$.

\section{References}

1. ASTM D86-15. Standard test method for distillation of petroleum products and liquid fuels at atmospheric pressure. PA: ASTM International, 2015. (http://www.astm.org)

2. Brusilovskiy A.I. Metodologiya i rezul'taty primeneniya kubicheskikh uravneniy sostoyaniya dlya modelirovaniya termodinamicheskikh svoystv prirodnykh uglevodorodnykh flyuidov. Aktual'nyye voprosy issledovaniy plastovykh sistem mestorozhdeniy uglevodorodov: $\mathrm{sb}$. nauch. statey v 2 ch. M.: Gazprom VNIIGAZ, 2011. ch. 2. P. 150-165. (Vesti gazovoy nauki). [in Russian]

3. Coats K.H., Smart G.T. (1986) Application of a regressionbased EOS PVT program to laboratory data, Society of Petroleum Engineers Reservoir Engineering, 1, 277-299.

4. Grigor'yev B.A., Brusilovskiy A.I. Zinchenko I.A. Matematicheskoye modelirovaniye plastovykh sistem, uravneniya sostoyaniya i fazovyye ravnovesiya plastovykh flyuidov i ikh komponentov. Vesti gazovoy nauki. 2016. No 4 (28). P. 13-20. [in Russian]

5. Pedersen K.S. et al. (1989) Characterization of gascondensate mixtures, in: Chorn L.G., Mansoori G.A. (edited by) C7+ fraction characterization. New York, Taylor \& Francis, 137-152.

6. Whitson C.H., Brule M.R. Phase Behavior. SPE Monograph Series, Volume 20. Richardson, Texas, 2000. 240 p.

7. Whitson C. H. Characterizing Hydrocarbon Plus Fractions. SPE Reservoir Engineering. 1983. P. 683-694. (SPE 12233)
8. Yushchenko T.S., Brusilovskiy A.I. Effektivnyy metod postroyeniya i adaptatsii PVTmodeley plastovykh flyuidov gazokondensatnykh mestorozhdeniy i gazovykh shapok neftegazokondensatnykh zalezhey. Neftyanoye khozyaystvo. 2015. No 1. P. 56-60. [in Russian]

9. Zotov G.A., Aliyev Z.S. Instruktsiya po kompleksnomu issledovaniyu gazovykh i gazokondensatnykh plastov i skvazhin. M.: Nedra, 1980. 301 p. [in Russian]

10. Brusilovskiy A.I. Fazovyye prevrashcheniya pri razrabotke mestorozhdeniy nefti i gaza. M.: Izdatel'skiy dom «Graal'», 2002. 579 p. [in Russian] 